https://doi.org/10.15407/ujpe65.3.254

O.A. YESHCHENKO, ${ }^{1}$ A.O. BARTENEV,${ }^{1}$ A.P. NAUMENKO,${ }^{1}$ N.V. KUTSEVOL,${ }^{2}$ IU.I. HARAHUTS, ${ }^{2}$ A.I. MARININ ${ }^{3}$

1 Taras Shevchenko National University of Kyiv, Physics Department (60, Volodymyrs'ka Str., Kyiv 01601, Ukraine; e-mail: yes@univ.kiev.ua)

2 Taras Shevchenko National University of Kyiv, Chemistry Department (60, Volodymyrs'ka Str., Kyiv 01601, Ukraine)

${ }^{3}$ National University of Food Technology, Problem Research Laboratory (68, Volodymyrs'ka Str., Kyiv 01601, Ukraine)

\title{
LASER-DRIVEN AGGREGATION IN DEXTRAN-GRAFT-PNIPAM/SILVER NANOPARTICLES HYBRID NANOSYSTEM: PLASMONIC EFFECTS
}

\begin{abstract}
The laser-induced aggregation in the thermosensitive dextran grafted-poly( $N$-isopropylacrylamide) copolymer/Ag nanoparticles (D-g-PNIPAM/AgNPs) hybrid nanosystem in water has been observed. The laser-induced plasmonic heating of Ag NPs causes the Lower Critical Solution Temperature (LCST) conformation transition in D-g-PNIPAM/AgNPs macromolecules which shrink during the transition. The shrinking decreases sharply the distance between the silver nanoparticles that launches the aggregation of Ag NPs and the appearance of plasmonic attractive optical forces acting between the nanoparticles. It has been shown that the approach of the laser wavelength to the surface plasmon resonance in Ag nanoparticles leads to a significant strengthening of the observed aggregation, which proves its plasmon nature. The laser-induced transformations in the D-g-PNIPAM/AgNPs nanosystem have been found to be essentially irreversible that differs principally them from the temperature-induced transformations. Such fundamental difference proves the crucial role of the optical forces arising due to the excitation of surface plasmons in Ag NPs.

Ke ywords: thermoresponsive polymer, silver nanoparticles, laser-induced structural transformations, plasmon heating, optical forces.
\end{abstract}

\section{Introduction}

The progress in nanotechnology and life sciences requires novel advanced hybrid materials based on the biocompatible polymers [1-6]. A special place among such polymers is thermosensitive polymers in which structural changes occur during the temperature variation such as the conformation transformation of a polymer macromolecule and the aggregation of macromolecules. Thermosensitive polymers allow one to create locally controlled actuators that can have various applications [1, 7-9]. Perhaps, the most famous among thermosensitive polymers is poly(N-isopropylacrylamide), (PNIPAM). This interest is due to the famous lower critical solution

(C) O.A. YESHCHENKO, A.O. BARTENEV,

A.P. NAUMENKO, N.V. KUTSEVOL,

IU.I. HARAHUTS, A.I. MARININ, 2020 temperature (LCST) behavior, where heating an aqueous solution of PNIPAM above $32{ }^{\circ} \mathrm{C}$ induces a phase transition [10-13]. Below this temperature, the PNIPAM macromolecules are hydrophilic, the polymer chains are swollen, and the polymer exists in the water soluble form. Above this temperature, the PNIPAM macromolecules become hydrophobic, water is expelled from the polymer chains, which leads to their contraction, and, subsequently, they shrink. Hydrophobic interactions among the polymer chains persist and lead to the aggregation of the polymer. However, the complete aggregation only occurs above a critical concentration of free PNIPAM [14]. Below the critical concentration (Guiner regime), PNIPAM mainly exists in a solution in the form of separate macromolecules $[11,14]$.

The LCST thermal behavior of PNIPAM-based polymers makes them promising for the use in med- 
ical applications such as drug carriers for drug delivery systems, diagnostic substance carriers, and as biosensors [15-17]. The transition temperature for linear PNIPAM is very close to the human skin. Thus, this polymer can be applied for photodynamic anticancer therapy $[18,19]$. For a larger window of applications, especially in the field of nanotechnology as drug delivery systems, LCST should be shifted to higher temperatures. Currently, the extensive research is going on with the purpose to tune the LCST temperature by a modification of the structure of thermosensitive polymers. The first possible way is a modification of the structure of a polymer molecule itself. It was shown that the branched structure of PNIPAM-containing polymers opens the possibility to tune the LCST [20, 21]. In particular, this applies to such polymer as star-like Dextrangraft-PNIPAM containing the dextran core and PNIPAM chains. The second possible way is the synthesis of hybrid macromolecules containing both a polymer molecule and metal/semiconductor/insulator nanoparticles (NPs). The particular attention should be paid to the metal NPs. On the one hand, the metal NPs have a high potential in the hyperthermia treatment at the cellular level [22-25] that is based on the effect of light-induced plasmonic heating of noble metal NPs (Ag NPs in particular). On the other hand, the Ag nanoparticles possess a remarkable biomedical application [26]. The hybrid materials with Ag NPs incorporated into the thermosensitive polymer matrix could be as a real achievement in drug delivery. They can combine the local chemotherapy or antibacterial therapy with the photo thermal anticancer treatment. This can shorten the treatment time and decrease the drug dosage. In this respect, PNIPAM has been proposed as a stimuli responsive carrier of NPs [27-29].

The influence of a light (laser) illumination on the structural transformations in hybrid thermosensitive polymers with embedded metal NPs is the actual topic of recent researches [30-34]. The physical nature of such influence is the light-induced excitation of the surface plasmon resonance (SPR) in metal NPs. First, the nonradiative decay of the surface plasmons causes the NP heating and the subsequent heat transfer from an NP to the surrounding medium that is called the plasmonic heating [35-39]. In the metal NPs, the heating of the medium is extremely localized. Therefore, the metal NPs serve as highly effi- cient localized heat sources on the nanometer-length scale. The heating effect should have a resonant character. Namely, the heating is especially strong, when the laser frequency is in resonance with the SPR frequency of a metal NP [40, 41]. The plasmonic heating has been shown to cause the phase transition in a surrounding medium, in particular, in hybrid thermosensitive polymer/metal NPs nanosystems [3034]. Second, besides the thermal action, the excitation of SPR in metal NPs by the laser illumination leads to the mechanical action on them. Light can induce the appearance of significant optical forces acting between the metal NPs [42-48]. When two metallic NPs are in a close proximity, and the pair is illuminated by the laser radiation, there is a laserinduced attractive force between them. When arrays of such NPs are suspended in a liquid, these forces can be used to promote the aggregation. The theoretical studies of these laser-induced attractive forces were performed in Refs. [45-48], where it was shown that the plasmonic attractive force has prominent resonant character, i.e. its strength increases strongly, when the frequency of laser light is in resonance with SPR in NPs. The action of attractive optical forces on NPs allows researchers to hold and manipulate them by means of optical tweezers in a variety of techniques $[49,50]$. Such forces are very important on the nanoscale because they can affect strongly the signal of surface enhanced spectroscopy $[51,52]$ or promote the controllable aggregation of NPs $[31,53,54]$.

In present work, we will study the laser-induced structural transformations in a hybrid nanosystem containing Ag NPs with star-like branched PNIPAM with Dextran core and grafted PNIPAM arms (Dg-PNIPAM/AuNPs) and their dependence on the detuning of a laser frequency at the SPR and on the laser illumination intensity. The surface plasmon resonance spectroscopy (extinction spectra) is used to study such transformations. The transformation of the extinction spectra of such system due to the shrinking of D-g-PNIPAM polymer macromolecules and the aggregation of silver NPs is observed. It will be shown that the approach of the laser radiation wavelength to the SPR wavelength leads to a significant strengthening of the observed effects, which proves their plasmon nature. The observed shrinking of D-g-PNIPAM macromolecules and the aggregation of silver NPs and D-g-PNIPAM molecules are interpreted as a result of the laser plas- 

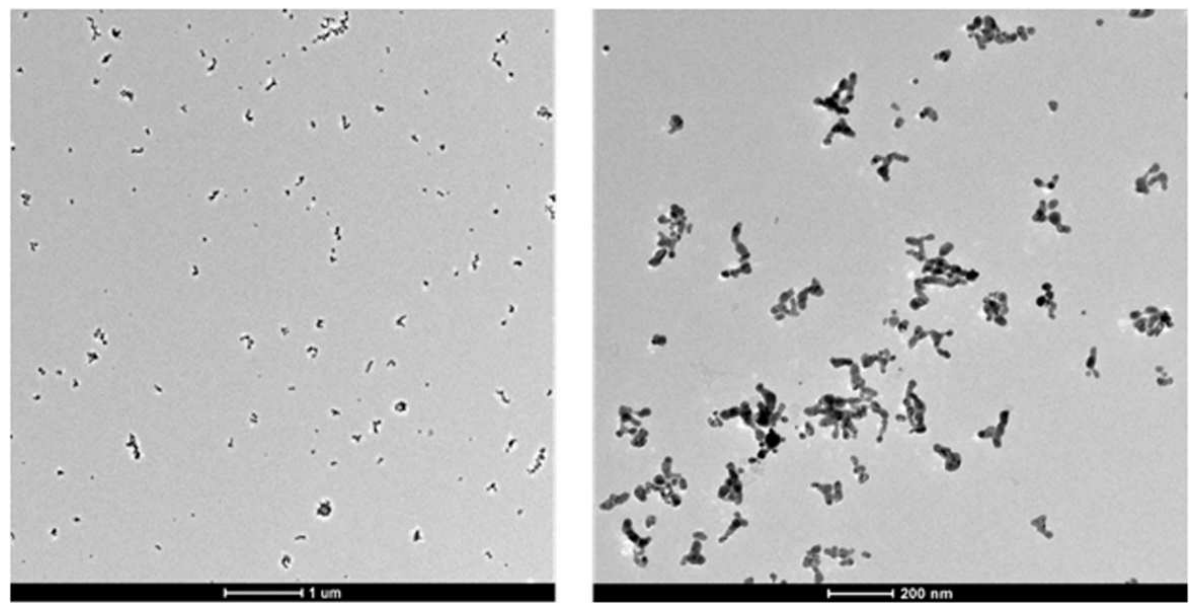

Fig. 1. TEM image of the D-g-PNIPAM/AgNPs hybrid nanosystem

mon heating of Ag NPs and the action of the optical plasmonic attraction forces between NPs due to the excitation of surface plasmons in the NPs by the resonant laser field. The increase in the laser intensity leads to enforcing the aggregation processes. The transformation of the extinction spectra of D-g-PNIPAM/AuNPs at a backward decrease in the laser intensity keeps its trend that proves the fact that the laser-induced formation of aggregates of D-g-PNIPAM/AuNPs macromolecules is irreversible. Thus, the present work together with our recent work [30] will show the irreversible character of laser-induced transformations (aggregation) in the D$\mathrm{g}-\mathrm{PNIPAM} / \mathrm{Ag}(\mathrm{Au}) \mathrm{NPs}$ hybrids that differ from the temperature-induced transformations which usually are reversible [11-13]. Such difference has been rationalized to be a result of the action of attractive optical forces between the Ag NPs that promote the formation of aggregates and counteract their destruction.

\section{Experimental}

\section{1. $D-g-P N I P A M / A g N P s$ nanosystem synthesis}

Initially, the star-like copolymer consisting of a dextran core with $M w=70 \times 10^{4} \mathrm{~g} / \mathrm{mol}$ and 15 PNIPAM grafts were synthesized. Through the text, this copolymer is labeled as D-g-PNIPAM. The synthesis and characterization of dextran-graft-poly(N-isopropylacrylamide) copolymers were reported in Refs. [11, 30, 55]. The reduction of $\mathrm{Ag}$ ions was performed in aqueous solutions of the polymer template $\mathrm{D}_{-} \mathrm{g}-$
PNIPAM using the $\mathrm{AgNO}_{3}$ aqueous solution as a source of silver. The synthesis and characterization of the aqueous solution of D-g-PNIPAM/AgNPs hybrids were reported in Ref. [55] in detail. The obtained samples were stored in cold and in dark. For further optical measurements, the stock solution was diluted to two different concentrations of Ag NPs: $0.023 \mathrm{mg} / \mathrm{ml}$ and $0.171 \mathrm{mg} / \mathrm{ml}$. The respective samples are labeled further in the text as the $L$ sample with a lower concentration of $0.023 \mathrm{mg} / \mathrm{ml}$ and the $H$ sample with a higher concentration of $0.171 \mathrm{mg} / \mathrm{ml}$.

\subsection{Transmission electron microscopy (TEM)}

For the sample preparation, 400 mesh $\mathrm{Cu}$ grids with a plane carbon film were made hydrophilic by a glow discharge treatment (Elmo, Cordouan Technologies, Bordeaux, France). A $5 \mu \mathrm{l}$ drop was deposited and let adsorbed for $1 \mathrm{~min}$. Then the excess of a solution was removed with a piece of filter paper. TEM measurements were carried on two TEMs, Tecnai G2 or CM12 (FEI, Eindhoven, Netherlands), and the images were obtained with a ssCCD Eagle camera on the Tecnai and a Megaview SIS Camera on the CM12. The typical TEM images of the D-g-PNIPAM/AuNPs nanosystem obtained at temperature of $25{ }^{\circ} \mathrm{C}$ are presented in Fig. 1. It is seen that there are single Ag NPs and aggregates of NPs. Obviously, the NPs are located inside the macromolecules. The single Ag NPs have the spherical shape and their mean size is $15 \mathrm{~nm}$.

ISSN 2071-0194. Ukr. J. Phys. 2020. Vol. 65, No. 3 


\subsection{Dynamic light scattering (DLS)}

DLS measurements were carried out by using a Zetasizer Nano ZS90 (Malvern Instruments, UK). The apparatus contains a $4 \mathrm{~mW} \mathrm{He}-\mathrm{Ne}$ laser with a wavelength $632.8 \mathrm{~nm}$, and the scattered light is detected at an angle of $173^{\circ}$ (back scattering). The correlograms of the $L$ and $H$ samples were collected at room temperature, $25^{\circ} \mathrm{C} .20$ correlation curves were processed by the CONTIN algorithm [56] which is known to be reliable in getting the hydrodynamic diameter (size) distributions for complicated systems [56]. The CONTIN algorithm was realized using the MATLAB program rilt.m [57].

\subsection{Light extinction with simultaneous laser illumination}

The light extinction (optical density) spectra were measured using a Cary 60 UV-VIS spectrophotometer (Agilent Technologies). The D-g-PNIPAM/AgNPs and D-g-PNIPAM aqueous solutions were placed in a $1 \times 1 \times 5-c m$ polished cell. We studied the influence of the diode cw laser illumination on the extinction spectra of the aqueous solutions of $\mathrm{D}-\mathrm{g}-$ PNIPAM/AgNPs hybrids for samples with different concentrations of Ag NPs (lower $C=0.023 \mathrm{mg} / \mathrm{ml}$ for $L$ sample and higher $C=0.171 \mathrm{mg} / \mathrm{ml}$ for $H$ sample). During the measurement of extinction spectra, the exciting laser beam and the probing beam of a Xe-lamp were spatially aligned. Respectively, spectra from the laser-illuminated area of the solution were measured. The angle between the laser and Xe-lamp beams was $90^{\circ}$. The time interval between the measurements of spectra at different laser intensities was $5 \mathrm{~min}$. Thus, the laser heating and cooling of the sample were carried out quite slowly to equilibrate the temperature of the sample. The dependences of the extinction spectra on the laser wavelength and the illumination intensity were analyzed. The lasers with the wavelengths of $405 \mathrm{~nm}, 445 \mathrm{~nm}$, and $655 \mathrm{~nm}$ were used. The radiation of a 405-nm laser is in the approximate resonance with the SPRs of single Ag NPs and aggregates of $\mathrm{Ag}$ NPs located in the volume of isolated polymer macromolecules. The radiation of a 445-nm laser is in the approximate resonance with SPR of the aggregates of Ag NPs located in the volume of aggregates of polymer macromolecules. The radiation of a $655-\mathrm{nm}$ laser is off-resonant with any of SPRs in the studied nanosystem. Each sample

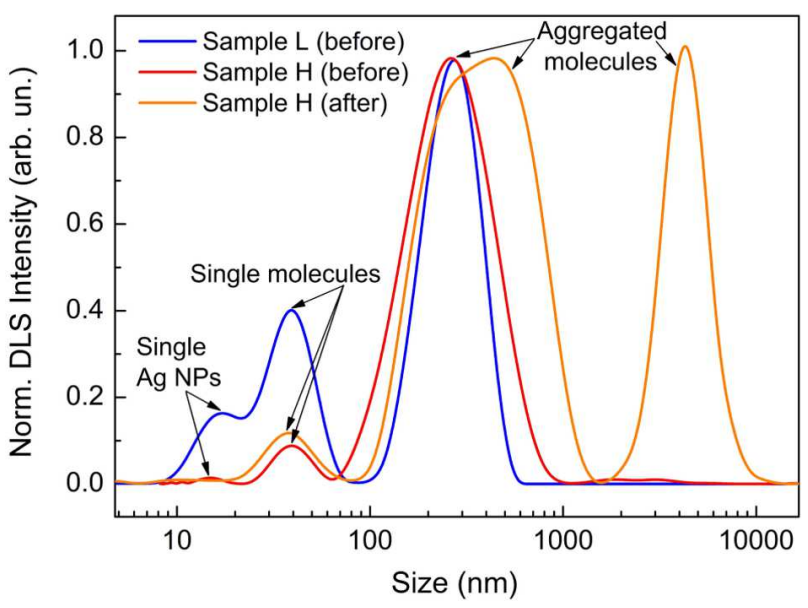

Fig. 2. Size (hydrodynamic diameter) distributions for the Dg-PNIPAM/AgNPs nanosystem: Before a cycle of irradiation by a 405-nm laser for sample $L$ (blue line) and sample $H$ (red line); and after the irradiation cycle for sample $H$ (orange line). DLS data have been measured at a temperature of $25{ }^{\circ} \mathrm{C}$

was treated by a cycle of the laser illumination during which the laser intensity was gradually increased from 0 up to maximal value with a further decrease down to 0 . The laser intensity variation intervals were the following: $0-12.8 \mathrm{~W} / \mathrm{cm}^{2}$ for a $405-\mathrm{nm}$ laser, 0 $19.2 \mathrm{~W} / \mathrm{cm}^{2}$ for a $445-\mathrm{nm}$ laser, and $0-16.8 \mathrm{~W} / \mathrm{cm}^{2}$ for a $655-\mathrm{nm}$ laser.

\section{Results and Discussion}

\subsection{Dynamic light scattering by the D-g-PNIPAM/AuNPs hybrid nanosystem}

The DLS measurements for an aqueous solution of the laser-untreated D-g-PNIPAM/AgNPs hybrid nanosystem were performed to analyze the size (hydrodynamic diameters) of studied nanoobjects, Fig. 2. The measurements were performed at a room temperature of $25^{\circ} \mathrm{C}$. It is seen that both size distribution curves have three characteristic size peaks: $15 \mathrm{~nm}, 40 \mathrm{~nm}$, and $265 \mathrm{~nm}$. Such three peaks coincide with high accuracy. The first size (15 nm) corresponds to single (isolated) Ag NPs that agrees with TEM data. The second size $(40 \mathrm{~nm})$ corresponds to a single (isolated) $\mathrm{D}-\mathrm{g}-\mathrm{PNIPAM} / \mathrm{AgNPs}$ macromolecule. The third size $(265 \mathrm{~nm})$ corresponds to the aggregates of D-g-PNIPAM/AgNPs macromolecules. Thus, one can conclude that both initial, i.e., laser-untreated $L$ and $H$ samples contain single 


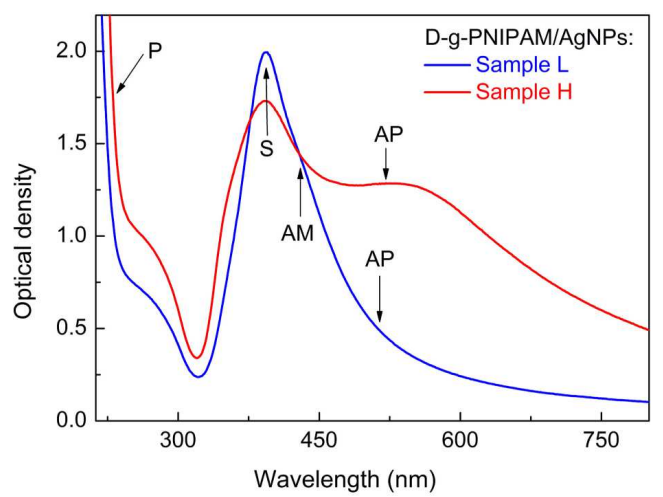

$a$

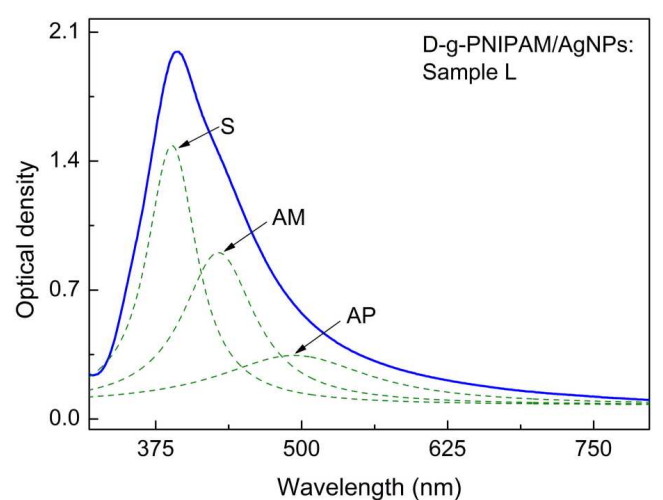

$b$

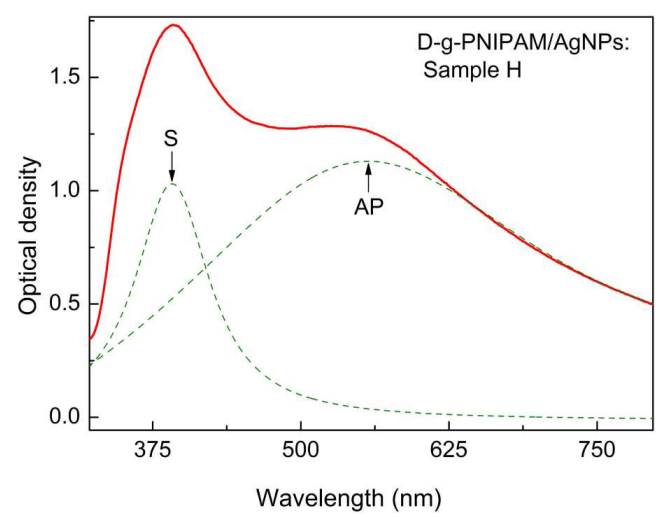

$c$

Fig. 3. (a) - Extinction spectra of the D-g-PNIPAM/AgNPs nanosystem for sample $L$ (blue line) and sample $H$ (red line). (b) and $(c)$ present the Lorentzian peak fitting of the extinction spectra of samples $L$ and $H$, correspondingly. Designations are the following: $P$ - extinction peak of D-g-PNIPAM, $S-$ SPR peak of the single (isolated) Ag NPs, $A M-$ SPR peak of the aggregates of $\mathrm{Ag} \mathrm{NPs}$ formed in the volume of single D-gPNIPAM macromolecules (monoaggregates), AP - SPR peak of the D-g-PNIPAM/AgNPs aggregates containing several aggregated D-g-PNIPAM macromolecules (polyaggregates) hybrid macromolecules and aggregated ones. To compare quantitatively the relative concentrations of the single and aggregated molecules, we have presented the normalized size distributions in Fig. 2. It is clearly seen two facts. The first one is that the aggregates of D-g-PNIPAM/AgNPs macromolecules predominate in the $H$ sample, while the $L$ sample is characterized by a quite high relative concentration of single macromolecules. The second one is a quite high relative concentration of single Ag NPs in the $L$ sample comparing to the $H$ sample.

We have revealed in our recent work [12] that the temperature-induced LCST conformation transition in an aqueous solution of D-g-PNIPAM/AgNPs hybrid macromolecules leads to the aggregation of the macromolecules. Another important fact, revealed in our work [12], is that the direct heating at temperatures higher than the LCST point does not change the size of D-g-PNIPAM/AgNPs aggregates. Let us note that, as we show below, such behavior of the size of D-g-PNIPAM/AgNPs aggregates at temperatures higher that the LCST point differs essentially from the behavior at the laser illumination of this nanosystem.

\subsection{Evolution of extinction spectra of the $D-g-P N I P A M / A g N P s$ hybrid nanosystem under laser illumination}

Now, we consider the dependence of the evolution of the extinction spectra of a D-g-PNIPAM/AgNPs aqueous solution on the laser wavelength and the illumination intensity. The spectra of $\mathrm{D}-\mathrm{g}-$ PNIPAM/AgNPs for $L$ and $H$ samples untreated by the laser radiation are presented in Fig. 3, a. The result of the fitting of peaks on the section of the spectra related to SPRs in Ag NPs in the studied nanohybrids by the Lorentz peaks is shown in Figs. $3, b$ and $c$. It follows from the DLS data that the untreated samples contain both isolated macromolecules and their aggregates. Therefore, the extinction spectra of $\mathrm{D}_{-}$ g-PNIPAM/AgNPs for $L$ and $H$ samples contain a variety of plasmonic extinction peaks. Those are: $S$ peak of SPR of single isolated Ag NPs embedded in D-g-PNIPAM macromolecules, $A M$ peak of SPR of the aggregates of Ag NPs located in the volume of isolated D-g-PNIPAM macromolecules (further named as Ag NPs monoaggregates), and $A P$ peak of SPR of the aggregates of $\mathrm{Ag}$ NPs located in the volume 


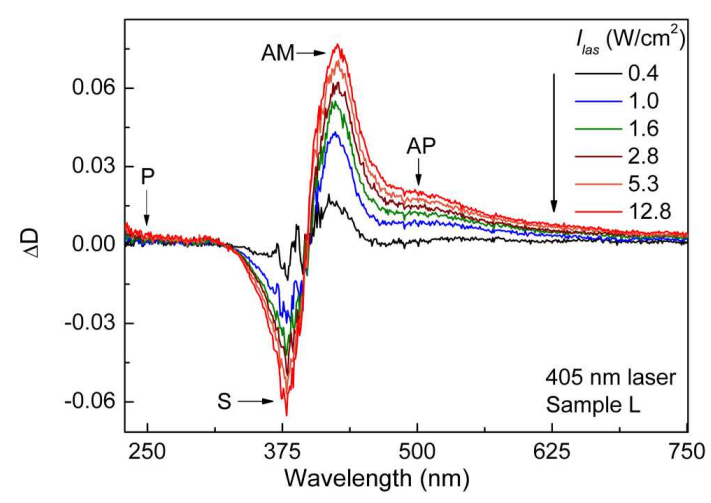

$a$

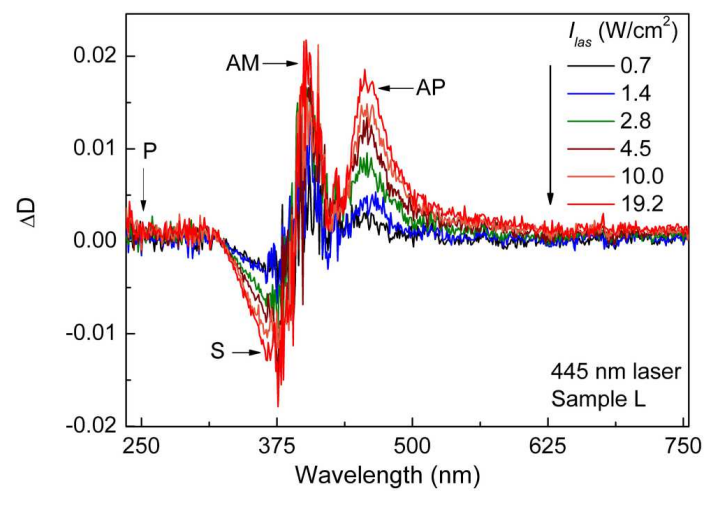

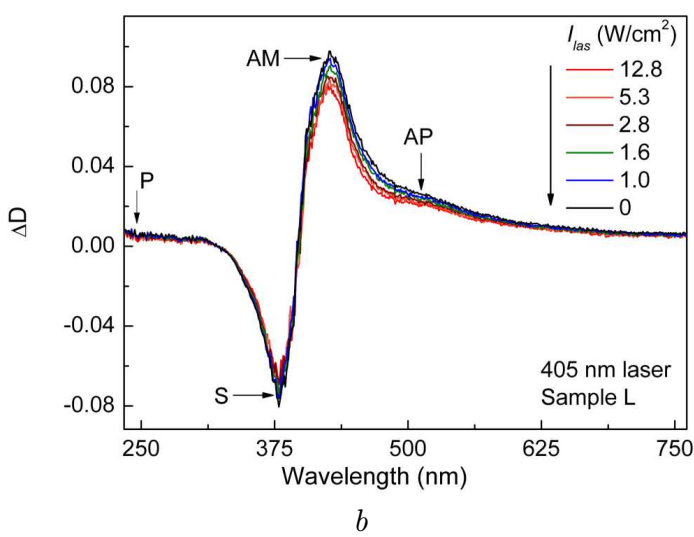

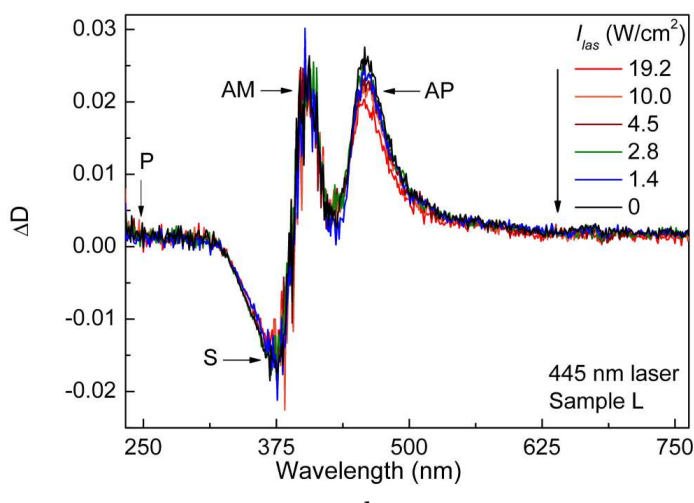

Fig. 4. Difference extinction spectra $(\Delta D(I)=D(I)-D(0))$ of the D-g-PNIPAM/AgNPs nanosystem for sample $L$ in dependence on the laser illumination intensity, where $D(I)$ is the optical density at the laser intensity $I$, and $D(0)$ is one before the laser illumination. $(a)$ and $(b)$ show the evolution of the difference spectrum at the increase and the consequent decrease of the 405-nm laser illumination intensity, correspondingly. $(c)$ and $(d)$ - the same for the 445-nm laser illumination

of aggregated D-g-PNIPAM macromolecules (further named as Ag NPs polyaggregates). In addition, there is an increase of the extinction at wavelengths shorter than $250 \mathrm{~nm}$ that is a low-energy wing of the extinction $P$ band of $\mathrm{D}-\mathrm{g}-\mathrm{PNIPAM}$ polymer, Fig. 3, $a$.

Let us consider the influence of the laser illumination on the extinction spectra of $\mathrm{D}-\mathrm{g}-$ PNIPAM/AgNPs. To see the laser-induced changes more pronounced, we present the difference spectra $\Delta D(I)=D(I)-D(0))$, where $D(I)$ is the optical density at the laser intensity $I$, and $D(0)$ is one before the laser illumination. Figures 4, $a$ and (b) show the evolution of the difference spectrum for $L$ sample at the increase of the $405-\mathrm{nm}$ laser intensity from 0.4 to $12.8 \mathrm{~W} / \mathrm{cm}^{2}$ and at its backward decrease from $12.8 \mathrm{~W} / \mathrm{cm}^{2}$ to 0 . It is clearly seen that, as the laser intensity increases, the area of $S$ peak corresponding to isolated Ag NPs decreases, while the areas of $A M$ and $A P$ peaks of aggregated NPs increase. Such behavior evidently proves the fact that the laser intensity increase intensifies the $\mathrm{Ag}$ NPs aggregation. Indeed, a decrease of the $S$ peak area reflects a decrease of the concentration of the isolated $\mathrm{Ag} \mathrm{NPs}$, while an increase of the areas of $A M$ and $A P$ peaks reflects an increase of the aggregated Ag NPs. The physical mechanisms of aggregation are discussed in Subsection 3.3 in detail. Here, let us just note that those are the conformational phase transition in a D-g-PNIPAM macromolecule with its shrinking and the action of laser-induced plasmonic attractive forces between the Ag NPs. Meanwhile, let us note that an increase of the area of $A M$ peak is sufficiently more pronounced than one of $A P$ peak. This means that the illumination at $405 \mathrm{~nm}$ causes mainly the formation of $\mathrm{Ag}$ NPs aggregates in the volume of isolated macromolecules. This is quite expectable, 




$a$

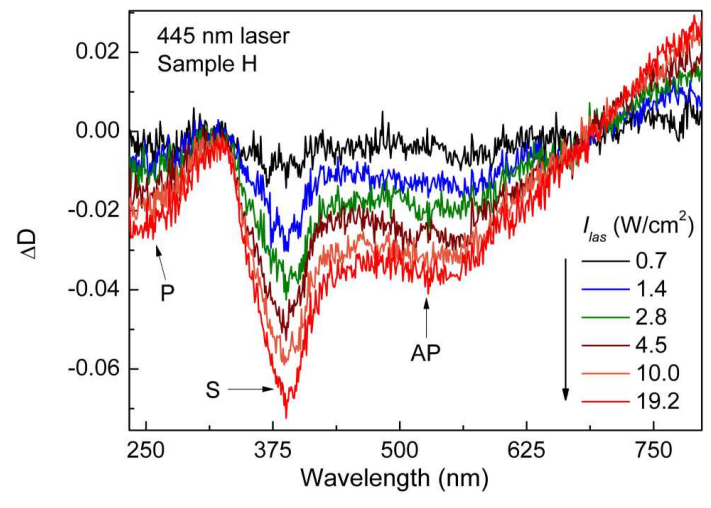

$c$

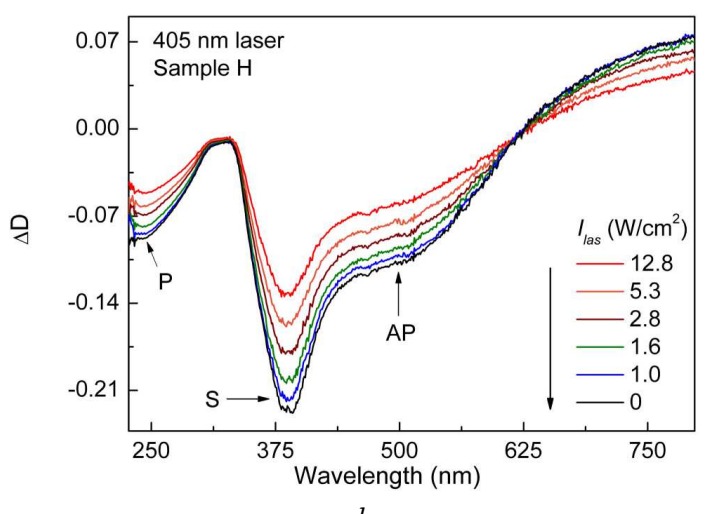

$b$

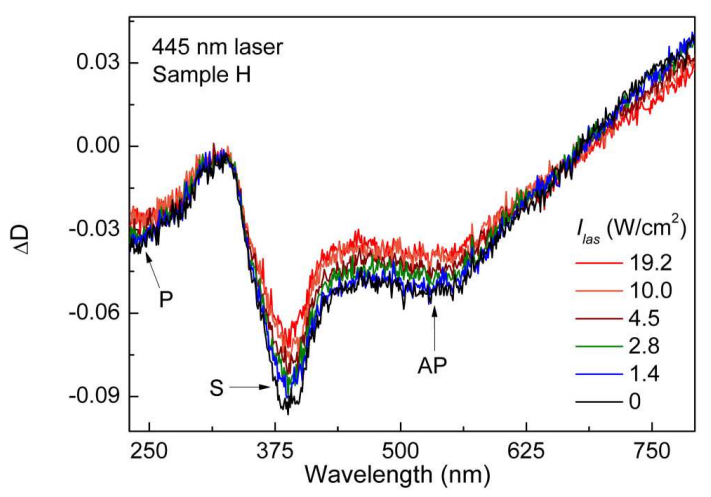

$d$

Fig. 5. Difference extinction spectra $(\Delta D(I)=D(I)-D(0))$ of the D-g-PNIPAM/AgNPs nanosystem for sample $H$ in dependence on the laser illumination intensity, where $D(I)$ is the optical density at the laser intensity $I$, and $D(0)$ is one before the laser illumination. $(a)$ and $(b)$ show the evolution of the difference spectrum at the increase and the consequent decrease of the 405-nm laser illumination intensity, correspondingly. $(c)$ and $(d)$ - the same for the 445-nm laser illumination

because a 405-nm laser is resonant with SPRs in isolated Ag NPs and their monoaggregates. Correspondingly, the 405-nm laser radiation causes the plasmon heating and the appearance of optical forces for these Ag NPs. Meanwhile, a 405-nm laser is farther from SPR of polyaggregates of Ag NPs, and, therefore, the formation of such aggregates occurs quite slightly. It is seen that, at the backward decrease of the laser intensity, the trends remain the same, i.e., the area of $S$ peak decreases, while the areas of $A M$ and $A P$ peaks increase. Thus, the aggregation goes on, but its rate slows down. It is worth to note that the area of polymer $P$ peak is not changed, by indicating that the concentration of D-g-PNIPAM macromolecules is not changed in the solution.

Let us consider the influence of the 445-nm laser illumination on the $L$ sample. Figs. $4, c$ and $d$ show the evolution of the difference spectrum for this sam- ple at the increase of the 445-nm laser intensity from 0.7 to $19.2 \mathrm{~W} / \mathrm{cm}^{2}$ and at its backward decrease from $19.2 \mathrm{~W} / \mathrm{cm}^{2}$ to 0 . It is seen that trends of the behavior of the difference spectra are the same comparing to ones observed for a 405-nm laser. Those are a decrease of the area of $S$ peak, an increase of the areas of $A M$ and $A P$ peaks, the constancy of the area of $P$ peak, as well as a slight change of the spectrum at the backward decrease of the laser intensity. However, there is a principal difference comparing to case of a 405-nm laser. This is a considerably stronger increase of the area of $A P$ peak which is even stronger than an increase of $A M$ peak. This observation reflects the fact of a more efficient formation of polyaggregates of $\mathrm{Ag} \mathrm{NPs}$. This is quite expectable, since the 445-nm laser radiation is resonant with $\mathrm{SPR}$ of polyaggregates of Ag NPs that causes a stronger plasmon heating and stronger optical forces for such NPs.

ISSN 2071-0194. Ukr. J. Phys. 2020. Vol. 65, No. 3 


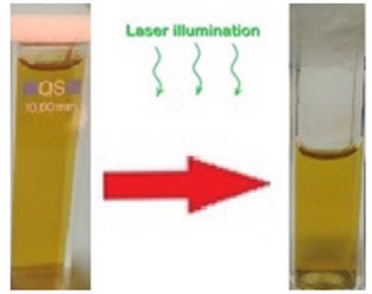

Sample L

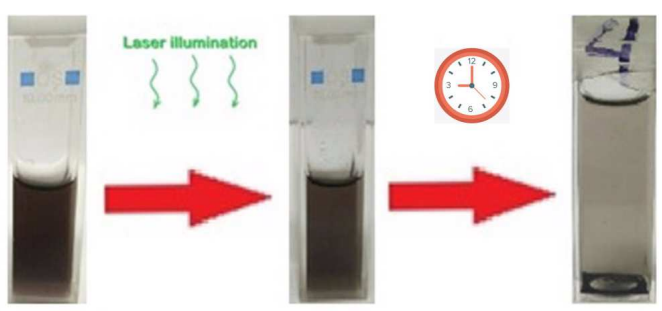

Sample H

Fig. 6. The change of the appearance of D-g-PNIPAM/AuNPs aqueous solution for $L$ and $H$ samples, respectively, after the cycle of their illumination by the 405-nm laser radiation. The appearance of $L$ sample remains almost unchanged, while the optical density of $H$ sample decreases noticeably. In 1 h after the illumination, the solution of $H$ sample becomes almost transparent due to the precipitation of large D-g-PNIPAM/AuNPs aggregates on the bottom of the cell

Now, let us consider the influence of the laser illumination on the properties of $H$ sample with a higher concentration of Ag NPs. Figures 5, $a$ and $b$ show the evolution of the difference spectrum for $H$ sample at the increase of the 405-nm laser intensity from 0.4 to $12.8 \mathrm{~W} / \mathrm{cm}^{2}$ and at its backward decrease from $12.8 \mathrm{~W} / \mathrm{cm}^{2}$ to 0 . It is seen that, unlike the spectrum of $L$ sample, the spectrum of $H$ sample contains only one peak originating from Ag NPs aggregates, namely, $A P$ peak. This agrees with DLS data indicating that D-g-PNIPAM exists in the $H$ sample in the form of aggregates. One can see that the 405-nm laser intensity increase leads to a decrease of the area of $S$ peak of isolated Ag NPs, which is similar to the case of $L$ sample. However, the area of $A P$ peak of $A g$ NPs poly-aggregates decreases at an increase of the laser intensity that is in full contrast with the case of the $L$ sample. It is seen that $A P$ peak shifts to lower frequencies and broadens with increasing the laser intensity. Another new observation is a decrease of the area of the polymer $P$ peak. All noted effects clearly indicate the fact of the formation of very large D-g-PNIPAM/AgNPs aggregates containing a large number of polymer macromolecules. It is seen that, at the backward decrease of the laser intensity, the trends remain the same, i.e., the areas of all the peaks decrease. Thus, the aggregation goes on, but its rate slows down. Figures 5, $c$ and $d$ present the evolution of the difference spectrum for $H$ sample at the increase of the $445-\mathrm{nm}$ laser intensity from 0.7 to $19.2 \mathrm{~W} / \mathrm{cm}^{2}$ and at its backward decrease from $19.2 \mathrm{~W} / \mathrm{cm}^{2}$ to 0 . It is seen that the trends in the behavior of the spectra at a change of the laser intensity are the same as in case of $405 \mathrm{~nm}$.
We also studied the evolution of the spectra of $L$ and $H$ samples at their illumination by the offresonant radiation of a $655-\mathrm{nm}$ laser. In this case, no noticeable changes were observed. It is seen in Figs. 4 and 5 that the magnitude of the changes in the spectra is higher for the illumination by a $405-\mathrm{nm}$ laser than by a $445-\mathrm{nm}$ one. Thus, one can conclude that an increase of the detuning of the laser wavelength from SPR of Ag NPs leads to a decrease of the changes in the spectra. This means that the structural transformations in the D-g-PNIPAM/AgNPs nanosystem have the evident resonant character that proves their plasmonic nature.

Another important observation is that the changes in the spectra of the $H$ sample with a higher concentration of Ag NPs are sufficiently stronger than ones for the $L$ sample with a lower concentration, Figs. 4 and 5. At the illumination of the $H$ sample by a 405$\mathrm{nm}$ laser, the decrease of the optical density is very strong that has been above rationalized as a result of the formation of very large D-g-PNIPAM/AgNPs aggregates which precipitate on the bottom of the cell. This our assumption agrees entirely with the visual observation, Fig. 6 . After the cycle of illumination by a $405-\mathrm{nm}$ laser, the appearance of the $L$ sample remains almost unchanged, while the optical density of the $H$ sample decreases noticeably. In $1 \mathrm{~h}$ after the illumination, the solution of the $H$ sample becomes almost transparent due to the precipitation of large D-g-PNIPAM/AuNPs aggregates on the bottom of the cell. Moreover, the fact of the formation of very large D-g-PNIPAM/AgNPs aggregates in the $H$ sample after a cycle of the irradiation by a $405-$ $\mathrm{nm}$ laser has been proved by the DLS study, Fig. 2 (orange line). It is clearly seen that the laser irra- 
diation causes the appearance of two additional DLS peaks at $440 \mathrm{~nm}$ and $4.3 \mu \mathrm{m}$. The appearance of these peaks manifests the fact of the formation of aggregates larger than ones existing in the non-irradiated $H$ sample. The formation of the very large micronsized aggregates leads to their precipitation on the bottom of the cell, as it is seen in Fig. 6 .

\subsection{Physical mechanisms \\ of laser-induced structural transformations in the $D-g-P N I P A M / A g N P s$ hybrid nanosystem: discussion}

To analyze quantitatively the evolution of the areas of the peaks in the extinction spectra of the $\mathrm{D}-\mathrm{g}-$ PNIPAM/AgNPs hybrid nanosystem, we peak-fitted the spectra, Figs. 3, b and $c$. The obtained dependences of the peak areas on the laser intensity at its direct increase and the backward decrease for 405$\mathrm{nm}$ and 445-nm lasers are presented in Figs. 7, $a$ and $b$, respectively, for the $L$ sample. It is seen that, at the increase of the $405-\mathrm{nm}$ laser intensity up to $3 \mathrm{~W} / \mathrm{cm}^{2}$ and of the $445-\mathrm{nm}$ laser intensity up $7 \mathrm{~W} / \mathrm{cm}^{2}$, the rather sharp changes occur for the areas of all peaks. Namely, the area of $S$ peak of the single Ag NPs decreases, while the areas of $A M$ and $A P$ peaks of mono- and polyaggregates of $\mathrm{Ag}$ NPs increase. Evidently, such behavior reflects the fact of the conformation LCST transition in the macromolecules accompanied by their shrinking, which is due to the laser-induced plasmon heating of NPs. The shrinking leads to the abrupt decrease of the distance between the NPs that causes their aggregation. Correspondingly, the concentration of the single Ag NPs decreases, while the concentration of the aggregated ones increases. Let us note that the phenomenon of the temperature-induced aggregation of D-g-PNIPAM/AgNPs macromolecules was observed in our recent work [12]. We revealed in [12] that the direct heating at the temperatures higher than the LCST point does not change the size of $\mathrm{D}_{-} \mathrm{g}-$ PNIPAM/AgNPs aggregates.

However, in the present work, a further increase of the laser intensity leads to a further decrease of the area of $S$ peak and a simultaneous increase of the areas of $A M$ and $A P$ peaks. This reflects the fact of the continuation of the aggregation process, i.e., the size of the $\mathrm{D}-\mathrm{g}-\mathrm{PNIPAM} / \mathrm{AgNPs}$ aggregates varies. This means that, in addition to the laser- induced plasmon heating, there is another physical mechanism of aggregation. This is the appearance of the attractive optical forces acting between the Ag NPs due to the excitation of the SPR in NPs by the laser field [45-48]. The phenomenon of the aggregation in the similar D-g-PNIPAM/AuNPs hybrids caused by the action of optical plasmon forces has been observed in our recent work [30]. This our assumption of the role of plasmon optical forces in the aggregation is proved by the fact of the linear dependence of the areas of the extinction peaks on the laser intensity, Fig. 7. Indeed, as it has been reported in Refs. [45-48], a laser-induced attractive force between two metallic NPs located in a close proximity depends linearly on the laser power. It was shown in Refs. [45-48] that the plasmonic attractive force has a prominent resonant character, i.e. its strength increases strongly, when the laser light frequency is in resonance with SPR in NPs. When the resonance condition is fulfilled, the plasmonic force strength can be considerably higher than the strength of the van der Waals one. The resonant character of the observed laser-induced changes in the extinction spectra proves our assumption of the optical forces as well. It is seen that, at the backward decrease of the laser intensity, the trends in the dependences of the extinction peak areas on the laser intensity remain the same that reflects the fact that the aggregation goes on at a decrease of the laser intensity. Thus, one can conclude that the laser-induced structural transformations in the D-g-PNIPAM/AgNPs hybrid nanosystem is irreversible likely to the transformations in a similar Dg-PNIPAM/AuNPs nanosystem reported in Ref. [30] that is essentially different from the temperatureinduced transformations which are usually reversible [11-13]. Thus, it is reasonable to make conclusion of the crucial role of the optical plasmon forces in the aggregation process in the hybrid nanosystems of thermosensitive polymer/metal NPs types.

Figures $8, a$ and $b$ show the dependences of the peak areas on the laser intensity at its direct increase and the backward decrease for 405-nm and 445-nm lasers, respectively, for the $H$ sample with higher concentrations of D-g-PNIPAM and Ag NPs. It is seen that there are similarities and differences in the dependences for the $H$ sample as compare to ones for the $L$ sample. Namely, at the increase of the 405$\mathrm{nm}$ laser intensity up to about $3 \mathrm{~W} / \mathrm{cm}^{2}$ and of the $445-\mathrm{nm}$ laser intensity up about $7 \mathrm{~W} / \mathrm{cm}^{2}$, the

ISSN 2071-0194. Ukr. J. Phys. 2020. Vol. 65, No. 3 


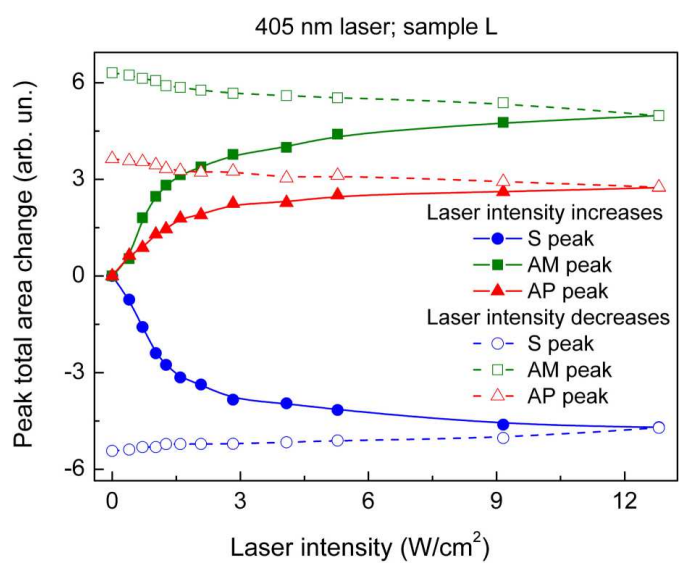

$a$



$b$

Fig. 7. Behavior of the total area of the plasmonic extinction $S$ peak of the single Ag NPs (blue circles and lines), $A M$ peak of $\mathrm{Ag}$ NP monoaggregates (green squares and lines), and $A P$ peak of Ag NP polyaggregates (red triangles and lines) occurring at the increase (filled symbols and solid lines) and the consequent decrease (hollow symbols and dashed lines) of the 405-nm laser (a) and 445-nm laser (b) illuminations. The data are presented for sample $L$

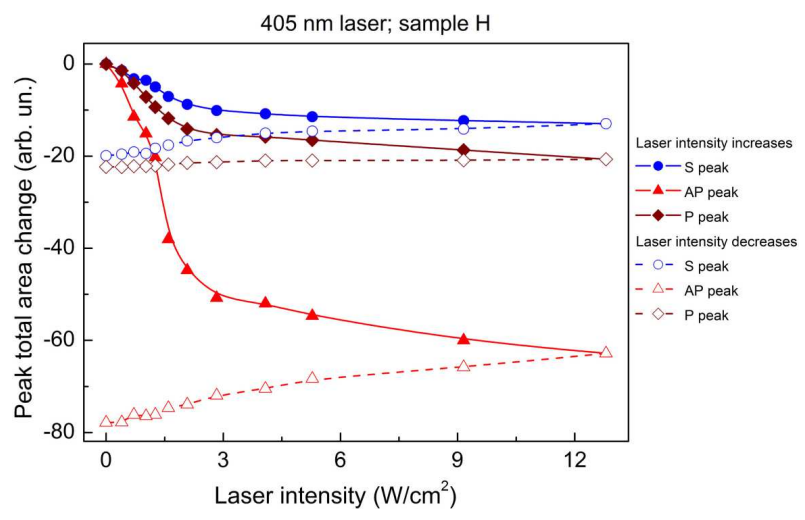

$a$

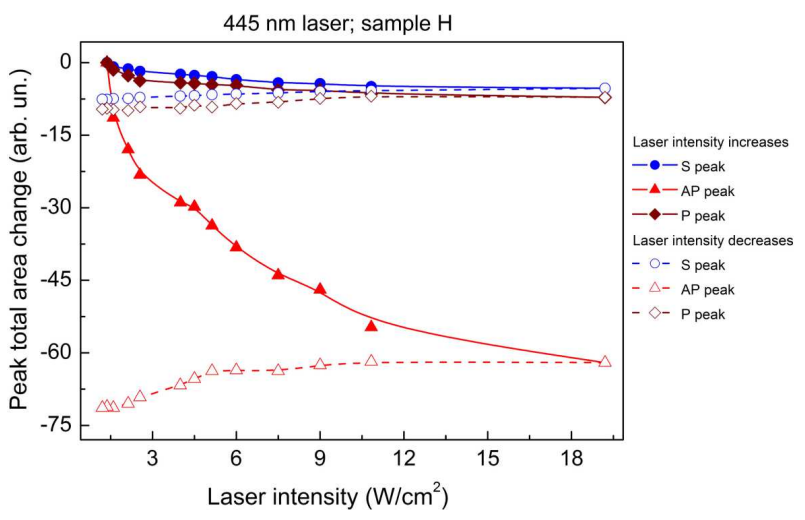

$b$

Fig. 8. Behavior of the total area of the plasmonic extinction $S$ peak of the single Ag NPs (blue circles and lines), $A P$ peak of Ag NP poly-aggregates (red triangles and lines), and $P$ peak of D-g-PNIPAM polymer (brown diamonds and lines) occurring at the increase (filled symbols and solid lines) and the consequent decrease (hollow symbols and dashed lines) of the 405-nm laser (a) and 445-nm laser (b) illuminations. The data are presented for sample $H$

rather sharp decrease of the areas of all the extinction peaks is observed. This concerns as plasmonic $S$ and $A P$ peaks of the single and polyaggregated $\mathrm{Ag}$ NPs and $P$ peak of bare D-g-PNIPAM polymer. Such abrupt decrease of the peak areas reflects the shrinking of polymer molecules due to LCST transition that causes the Ag NPs aggregation, as was discussed above. As we have noted above, since the concentrations of the polymer and Ag NPs in the $H$ sample are considerably higher than in the $L$ sample, the aggregation process causes the formation of very large D-g-PNIPAM/AgNPs aggregates that precipi- tate on the bottom of the cell. The precipitation leads to a considerable decrease of the optical density that manifests itself as a decrease of the areas of all the peaks. The further increase of the laser intensity leads to a gradual linear decrease of the areas of the peaks indicating the fact of the aggregation due to the action of the optical forces. Similarly to the $L$ sample, at the backward decrease of the laser intensity, the trends in the dependences of the extinction peak areas on the laser intensity remain the same, which reflects the fact that the aggregation goes on at a decrease of the laser intensity. Thus, the laser-induced structural 
transformation is irreversible for the $H$ sample as it is for the $L$ one.

Finally, let us discuss the following important observations which are seen in Figs. 4-8. First, the structural transformation in the $H$ sample with a higher concentration of Ag NPs is essentially more pronounced in comparison with ones in the $L$ sample. This proves the crucial role of Ag NPs in the transformation due to the phenomena of the plasmonic heating and plasmonic optical forces. Second, as we have noted above, the more pronounced changes in the spectra are observed at the illumination of the D-g-PNIPAM/AgNPs nanosystem by a 405$\mathrm{nm}$ laser which is resonant with SPR in the single Ag NPs. Meanwhile, at the use of a 445-nm laser which is resonant with the SPR in polyaggregates of $\mathrm{Ag} \mathrm{NPs}$, the changes in the spectra are essentially slighter. Most probably, it can be rationalized as following. The aggregates of Ag NPs embedded in D-g-PNIPAM/AgNPs macromolecules make them rigid. This counteracts the shrinking of molecules during the LCST transition. Meanwhile, the Dg-PNIPAM/AgNPs macromolecules containing the single Ag NPs are quite soft. Correspondingly, the shrinking is more sharp and pronounced in this case. Therefore, the excitation of the SPR in the single Ag NPs with their consequent heating leads to the sharp pronounced shrinking of a polymer molecule that causes the efficient launching of the process of aggregation. Meanwhile, the excitation of the SPR in the aggregates of Ag NPs embedded in the rigid Dg-PNIPAM/AgNPs macromolecules leads to a slight shrinking of the polymer molecule that makes the process of aggregation to be sufficiently less efficient.

\section{Conclusions}

In conclusion, the influence of the laser illumination on an aqueous solution of Dextran-grafted-PNIPAM/ AuNPs copolymer hybrid macromolecules has been studied. The $\mathrm{cw}$ diode lasers with the wavelengths of 405, 445, and $655 \mathrm{mn}$ have been used in experiments. The dynamic light scattering and extinction spectroscopy have been used to detect and analyze quantitatively the laser-induced structural transformations in this hybrid nanosystem. The evolution of surface plasmon extinction peaks during the cycle of increase/decrease of the laser intensity manifests the fact of the aggregation of Ag NPs both in the volume of the isolated polymer macromolecules and in the ag- gregates of macromolecules. The initial illumination at low laser intensities leads to the plasmonic heating that causes the shrinking of a macromolecule due to the LCST conformation transition. Such shrinking launches the process of aggregation of Ag NPs. Meanwhile, the shrinking causes an abrupt decrease of the distance between the NPs, which leads to the appearance of attractive optical forces acting between the NPs. Such forces have plasmonic nature, since their magnitude increases strongly at the approach of the laser wavelength to the wavelength of the surface plasmon resonance in $\mathrm{Ag}$ NPs. At the further illumination at higher laser intensities providing the temperatures higher than the LCST point, the sizes of the Ag NPs and D-g-PNIPAM/AgNPs aggregates increase linearly with an increase of the laser intensity proving the crucial role of the plasmonic optical forces in the formation of the aggregates. At the backward decrease of the laser intensity, the formation of the aggregates goes on. Correspondingly, after the turnoff the laser, the aggregates remain in the solution.

A decrease of the detuning of a laser wavelength from the SPR in Ag NPs leads to a stronger aggregation, which proves the plasmon nature of laser-induced transformations. We have revealed that the excitation of SPR in isolated Ag NPs causes the stronger aggregation comparing to the case of the excitation of SPR in aggregates of Ag NPs. Such phenomenon has been rationalized as following. The aggregates of Ag NPs embedded in D-g-PNIPAM/AgNPs macromolecules make them rigid. Respectively, the SPR excitation in such rigid D-g-PNIPAM/AgNPs macromolecules leads to a slight shrinking of the polymer molecule, which makes the process of aggregation to be sufficiently less efficient.

Thus, the laser-induced transformations in the Dg-PNIPAM/AgNPs nanosystem have been found to be essentially irreversible, which makes the laserinduced and temperature-induced structural transformations to be principally different. Such fundamental difference has been rationalized as a result of the action of optical forces arising due to the excitation of surface plasmons in Ag NPs. These attractive plasmonic forces facilitate the formation of the aggregates and counteract their destruction.

This work was supported in part by the Ministry of Education and Science of Ukraine (grant 0119U100319).

ISSN 2071-0194. Ukr. J. Phys. 2020. Vol. 65, No. 3 
1. M.A. Ward, T.K. Georgiu. Thermoresponsive polymers for biomedical applications. Polymer 3, 1215 (2011).

2. M. Joglecar, B.G. Trewyn. Polymer-based simuli responsible nanosystems for biomedial applications. Biotechology J. 8, 931 (2013).

3. E. Cabane, X. Zhang, K. Langowska, C.G. Palivan, W. Meier. Stimuli responsible polymers and their application in nanomedicine. Biointerphases 7, 1 (2012).

4. C. Gong, T. Qi, X. Wei, Y. Qu, Q. Wu, F. Luo, Z. Qian. Thermosensitive polymeric hydrogeles as drug delivery systems. Current Med. Chem. 20, 79 (2016).

5. V. Dal Lago, L. França de Oliveira, K. de Almeida Gonçalves, J. Kobarg, M.B. Cardoso. Size-selective silver nanoparticles: Future of biomedical devices with enhanced bactericidal properties. J. Mater. Chem. 21, 2267 (2011).

6. J.F. de Oliveira, M.B. Cardoso. Partial aggregation of silver nanoparticles induced by capping and reducing agents competition. Langmuir 30, 4879 (2014).

7. M.R. Aguilar, C. Elvira, A. Gallardo, B. Vázquez, J.S. Román. Smart polymers and their applications as biomaterials. III Biomaterials. In: Topics in Tissue Engineering Eds. by N. Ashammakhi, R. Reis, E. Chiellini (URL, 2007), Vol. 3, Chapter 6.

8. A. Gandhi, A. Paul, S.O. Sen, K.K. Sen. Studies on thermoresponsive polymers: Phase behaviour, drug delivery and biomedical applications. Asian J. of Pharmaceutical Sci. 10, 99 (2015).

9. O. Sedlácek, P. Cernoch, J. Kucka et al. Thermoresponsive polymers for nuclear medicine: which polymer is the best? Langmuir 32, 6115 (2016).

10. H. Du, R. Wickramasinghe, X. Qian. Effects of salt on the lower critical solution temperature of poly (N-isopropylacrylamide). J. Phys. Chem. B 114, 16594 (2010).

11. O.A. Yeshchenko, A.P. Naumenko, N.V. Kutsevol, D.O. Maskova, I.I. Harahuts, V.A. Chumachenko, A.I. Marinin. Anomalous inverse hysteresis of phase transition in thermosensitive dextran-graft-PNIPAM copolymer/Au nanoparticles hybrid nanosystem. J. Phys. Chem. C 122, 8003 (2018).

12. V. Chumachenko, N. Kutsevol, Iu. Harahuts, D. Soloviov, L. Bulavin, O. Yeshchenko, A. Naumenko, O. Nadtoka, A. Marinin. Temperature driven transformation in dextran-graft-PNIPAM/embedded silver nanoparticle hybrid system. Int. J. Polymer Sci. 2019, 3765614 (2019).

13. V.A. Turek, S. Cormier, B. Sierra-Martin, U.F. Keyser, T. Ding, J.J. Baumberg. The crucial role of charge in thermoresponsive-polymer-assisted reversible dis/assembly of gold nanoparticles. Advanced Optical Materials 2018, 1701270 (2018)

14. S.T. Jones, Z. Walsh-Korb, S.J. Barrow, S.L. Henderson, J. del Barrio, O.A. Scherman. The importance of excess poly(N-isopropylacrylamide) for the aggregation of poly(N-isopropylacrylamide)-coated gold nanoparticles. ACS Nano 10, 3158 (2016).

15. Y.M. Ma, D.X. Wei, H. Yao, L.P. Wu, G.Q. Chen. Synthesis, characterization and application of thermoresponsive polyhydroxyalkanoate-graft-poly(N-isopropylacrylamide). Biomacromolecules 17, 2680 (2016).

16. K.N. Plunkett, X. Zhu, J.S. Moore, D.E. Leckband. PNIPAM chain collapse depends on the molecular weight and grafting density. Langmuir 22, 4259 (2006).

17. A. Galperin, T.J. Long, B.D. Ratner. Degradable, thermo-sensitive poly(N-isopropyl acrylamide)-based scaffolds with controlled porosity for tissue engineering applications. Biomacromolecules 11, 2583 (2010).

18. G. Graziano. On the temperature-induced coil to globule transition of poly- $\mathrm{N}$-isopropylacrylamide in dilute aqueous solutions. Int. J. of Biological Macromolecules 27, 89 (2000).

19. V.C. Lopez, J. Hadgraft, M.J. Snowden. The use of colloidal microgels as a (trans)dermal drug delivery system. Intern. J. Pharmaceutics 292, 137 (2005).

20. A. Khanal, M.-P. N. Bui, S.S. Seo. Microgel-encapsulated methylene blue for the treatment of breast cancer cells by photodynamic therapy. J. Breast Cancer 17, 18 (2014).

21. W. Tao, L. Yan. Thermogelling of highly branched poly(Nisopropylacrylamide). J. Appl. Polymer Sci. 118, 3391 (2010).

22. E.C. Dreaden, L.A. Austin, M.A. Mackey, M.A. El-Sayed. Size matters: gold nanoparticles in targeted cancer drug delivery. Therapeutic Delivery 3, 457 (2012).

23. R. Mendes, P. Pedrosa, J.C. Lima, A.R. Fernandes, P.V. Baptista. Photothermal enhancement of chemotherapy in breast cancer by visible irradiation of gold nanoparticles. Sci. Reports 7, 10872 (2017).

24. R.S. Riley, E.S. Day. Gold nanoparticle-mediated photothermal therapy: Applications and opportunities for multimodal cancer treatment. WIREs Nanomedic. and Nanobiotech. 9, e1449 (2017).

25. M.R.K. Ali, I.M. Ibrahim, H.R. Ali, S.A. Selim, M.A. ElSayed. Treatment of natural mammary gland tumors in canines and felines using gold nanorods-assisted plasmonic photothermal therapy to induce tumor apoptosis. Intern. J. Nanomedicine 11, 4849 (2016).

26. L. Mei, Z. Lu, X. Zhang, C. Li, Y. Jia. Polymer$\mathrm{Ag}$ nanocomposites with enhanced antimicrobial activity against bacterial infection. ACS Applied Materials \& Interfaces, 6, 15813 (2014).

27. S.A. Abouelmagd, H. Hyun, Y. Yeo. Extracellularly activatable nanocarriers for drug delivery to tumors. Expert Opinion on Drug Delivery 11 (10), 1601 (2014).

28. H. Hatakeyama. Recent advances in endogenous and exogenous stimuli-responsive nanocarriers for drug delivery 
and therapeutics. Chemical and Pharmaceutical Bulletin 65, 612 (2017).

29. N. Kutsevol, A. Naumenko, V. Chumachenko, O. Yeshchenko, Yu. Harahuts, V. Pavlenko. Aggregation processes in hybrid nanosystem Polymer/Nanosilver/Cisplatine. Ukr. J. Phys. 63, 513 (2018).

30. O. Yeshchenko, A.P. Naumenko, N.V. Kutsevol, I.I. Harahuts. Laser-driven structural transformations in dextran-graft-PNIPAM copolymer/Au nanoparticles hybrid nanosystem: the role of plasmon heating and attractive optical forces. RSC Advances 8, 38400 (2018).

31. T. Ding, V.K. Valev, A.R. Salmon, C.J. Forman, S.K. Smoukov, O.A. Scherman, D. Frenkel, J.J. Baumberg. Light-induced actuating nanotransducers. Proceedings of Nat. Acad. Sci. of U.S.A. 113, 5503 (2016).

32. I. Aibara, S. Mukai, S. Hashimoto. Plasmonic-heatinginduced nanoscale phase separation of free poly(Nisopropylacrylamide) molecules. J. Phys. Chem. C 120, 17745 (2016).

33. I. Aibara, J. Chikazawa, T. Uwada, S. Hashimoto. Localized phase separation of thermoresponsive polymers induced by plasmonic heating. J. Phys. Chem. C 121, 22496 (2016).

34. S. Murphy, S. Jaber, C. Ritchie, M. Karg, P. Mulvaney. Laser flash photolysis of Au-PNIPAM core-shell nanoparticles: dynamics of the shell response. Langmuir 32, 12497 (2016).

35. A.O. Govorov, W. Zhang, T. Skeini, H. Richardson, J. Lee, N.A. Kotov. Gold nanoparticle ensembles as heaters and actuators: melting and collective plasmon resonances. Nanoscale Res. Lett. 1, 84 (2006).

36. A.O. Govorov, H.H. Richardson. Generating heat with metal nanoparticles. Nano Today 2, 30 (2007).

37. M.L. Brongersma, N.J. Halas, P. Nordlander. Plasmoninduced hot carrier science and technology. Nature Nanotechn. 10, 25 (2015).

38. G. Baffou, R. Quidant. Thermo-plasmonics: Using metallic nanostructures as nano-sources of heat. Laser $\&$ Photonics Reviews 7, 171 (2013).

39. Z. Fang, Y.R. Zhen, O. Neumann, A. Polman, F.J. García de Abajo, P. Nordlander, N.J. Halas. Evolution of lightinduced vapor generation at a liquid-immersed metallic nanoparticle. Nano Letters 13, 1736 (2013).

40. O.A. Yeshchenko, V.V. Kozachenko. Light-induced heating of dense $2 \mathrm{D}$ ensemble of gold nanoparticles: dependence on detuning from surface plasmon resonance. J. Nanopart. Res. 17, 296 (2015).

41. O.A. Yeshchenko, N.V. Kutsevol, A.P. Naumenko. Lightinduced heating of gold nanoparticles in colloidal solution: dependence on detuning from surface plasmon resonance. Plasmonics 11, 345 (2016).

42. J.J. Kingsley-Smith, M.F. Picardi, L. Wei, A.V. Zayats, F.J. Rodríguez-Fortuño. Optical forces from near-field di- rectionalities in planar structures. Phys. Rev. B 99, 235410 (2019).

43. K. Svoboda, S.M. Block. Optical trapping of metallic Rayleigh particles. Optics Letters 19, 930 (1994).

44. S. Sato, Y. Harada, Y. Waseda. Optical trapping of microscopic metal particles. Optics Letters 19, 1807 (1994).

45. J.R. Arias-González, M. Nieto-Vesperinas. Optical forces on small particles: Attractive and repulsive nature and plasmon-resonance conditions. J. Opt. Soc. of America A 20, 1201 (2003).

46. P. Chu, D.L. Mills. Laser-induced forces in metallic nanosystems: the role of plasmon resonances. Phys. Rev. Lett. 99, 127401 (2007).

47. J. Ng, R. Tang, C.T. Chan. Electrodynamics study of plasmonic bonding and antibonding forces in a biosphere. Phys. Rev. B 77, 195407 (2008).

48. A.J. Hallock, P.L. Redmond, L.E. Brus. Optical forces between metallic particles. Proceedings of Nat. Acad. of Sci. of U.S.A. 102, 1280 (2005).

49. A.S. Urban, S. Carretero-Palacios, A.A. Lutich, T. Lohmüller, J. Feldmann, F. Jäckel. Optical trapping and manipulation of plasmonic nanoparticles: fundamentals, applications, and perspectives. Nanoscale 6, 4458 (2014).

50. Y. Arita, G. Tkachenko, N. McReynolds, N. Marro, W. Edwards, E.R. Kay, K. Dholakia. Optical trapping of ultrasmooth gold nanoparticles in liquid and air. APL Photonics 3, 070801 (2018).

51. H. Xu, M. Kall. Surface-plasmon-enhanced optical forces in silver nanoaggregates. Phys. Rev. Lett. 89, 246802 (2002).

52. F. Svedberg, Z. Li, H. Xu, M. Kall. Creating hot nanoparticle pairs for surface-enhanced Raman spectroscopy through optical manipulation. Nano Letters 6, 2639 (2006).

53. D. Fava, M.A. Winnik, E. Kumacheva. Photothermally triggered self-assembly of gold nanorods. Chem. Commun. 18, 2571 (2009).

54. K. Murakoshi, Y. Nakato. Formation of linearly arrayed gold nanoparticles on gold single-crystal surfaces. Adv. Materials 12, 791 (2000).

55. V. Chumachenko, N. Kutsevol, Y. Harahuts, M. Rawiso, A. Marinin, L. Bulavin. Star-like dextran-graft-PNiPAM copolymers. Effect of internal molecular structure on the phase transition. J. Mol. Liq. 235, 77 (2017).

56. A. Scotti, W. Liu, J.S. Hyatt et al. The CONTIN algorithm and its application to determine the size distribution of microgel suspensions. J. Chem. Phys. 142, 234905 (2015).

57. O. Peña-Rodríguez, P.P. González Pérez, U. Pal. MieLab: A software tool to perform calculations on the scattering of electromagnetic waves by multilayered spheres. Intern. J. Spectroscopy 2011, 583743, (2011).

Received 26.09.19 ISSN 2071-0194. Ukr. J. Phys. 2020. Vol. 65, No. 3 
О.А. Єщенко, О.О. Бартенев, А.П. Науменко, Н.В. Кучевол, Ю.І. Гарагуи, А.І. Марінін

\section{ЛАЗЕРНО-ІНДУКОВАНА}

АГРЕГАЦІЯ В ГІБРИДНІЙ НАНОСИСТЕМІ “ДЕКСТРАН-ГРАФТ-РNIPАМ/НАНОЧАСТИНКИ СРІБЛА”: ПЛАЗМОННІ ЕФЕКТИ

Р е $з$ ю м е

Було виявлено процеси лазерно-індукованої агрегації в термочутливій гібридній наносистемі “декстран-графт-полі(Nізопропілакриламід)/наночастинки Ag” (D-g-PNIPAM/HЧ $\mathrm{Ag})$ у воді. Лазерно-індуковане плазмонне нагрівання НЧ $\mathrm{Ag}$ спричиняє конформаційний LCST-перехід у макромолекулах D-g-PNIPAM/HЧ Ag, які стискаються під час пере- ходу. Стиснення макромолекул приводить до різкого зменшення відстані між наночастинками срібла, що спричиняє початок процесів агрегації наночастинок $\mathrm{Ag}$ та виникнення плазмонних оптичних сил притягання між НЧ. Показано, що наближення довжини хвилі лазера до поверхневого плазмонного резонансу в наночастинках $\mathrm{Ag}$ приводить до значного посилення процесів агрегації, що підтверджує іiі плазмонну природу. Лазерно-індуковані перетворення в наносистемі D-g-PNIPAM/НЧ Ag виявилися суттєво незворотними, що принципово відрізняє їх від термоіндукованих перетворень. Така принципова відмінність доводить вирішальну роль оптичних ефектів, що виникають у досліджуваній гібридній наносистемі внаслідок збудження поверхневих плазмонів в наночастинках Ag. 